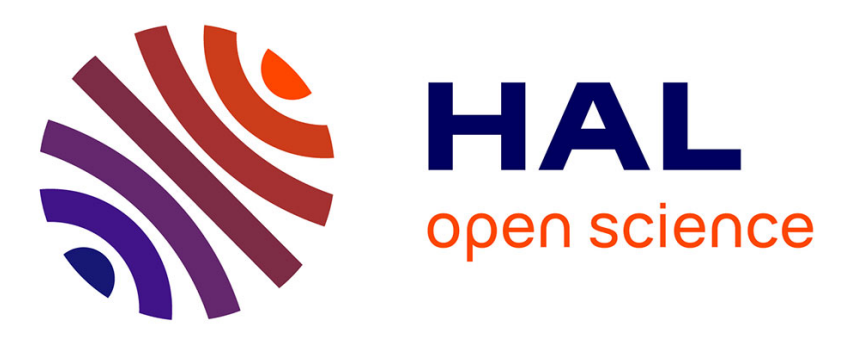

\title{
Photoisomerization of IC3N - An experimental and theoretical study
}

A. Guzik, M. Gronowski, M. Turowski, Jean-Claude Guillemin, R. Kolos

\section{To cite this version:}

A. Guzik, M. Gronowski, M. Turowski, Jean-Claude Guillemin, R. Kolos. Photoisomerization of IC3N - An experimental and theoretical study. Journal of Photochemistry and Photobiology A: Chemistry, 2020, 395, pp.112470. 10.1016/j.jphotochem.2020.112470 . hal-02569948

\section{HAL Id: hal-02569948 \\ https://hal-univ-rennes1.archives-ouvertes.fr/hal-02569948}

Submitted on 12 May 2020

HAL is a multi-disciplinary open access archive for the deposit and dissemination of scientific research documents, whether they are published or not. The documents may come from teaching and research institutions in France or abroad, or from public or private research centers.
L'archive ouverte pluridisciplinaire HAL, est destinée au dépôt et à la diffusion de documents scientifiques de niveau recherche, publiés ou non, émanant des établissements d'enseignement et de recherche français ou étrangers, des laboratoires publics ou privés. 


\section{Photoisomerization of $\mathrm{IC}_{3} \mathrm{~N}$. An experimental and theoretical study.}

A. Guzik, ${ }^{a}$ M. Gronowski, ${ }^{b}$ M. Turowski, ${ }^{*, b, c}$ J.-C. Guillemin, ${ }^{\text {d R. Kołos }}{ }^{\text {b }}$

${ }^{a}$ Cardinal Wyszyński University, Faculty of Mathematics and Natural Sciences, School of Exact Sciences, Wóycickiego 1/3 building 21, 01-938 Warsaw, Poland.

b Institute of Physical Chemistry, Polish Academy of Sciences, Kasprzaka, 44/52, 01-224

Warsaw, Poland.

${ }^{c}$ Department of Chemistry and Biochemistry, University of Colorado, Boulder, Colorado 803090215, United States.

d Univ Rennes, Ecole Nationale Supérieure de Chimie de Rennes, CNRS, ISCR - UMR6226, F35000 Rennes, France.

* corresponding author, mturowski@protonmail.com

\section{Graphical Abstract}




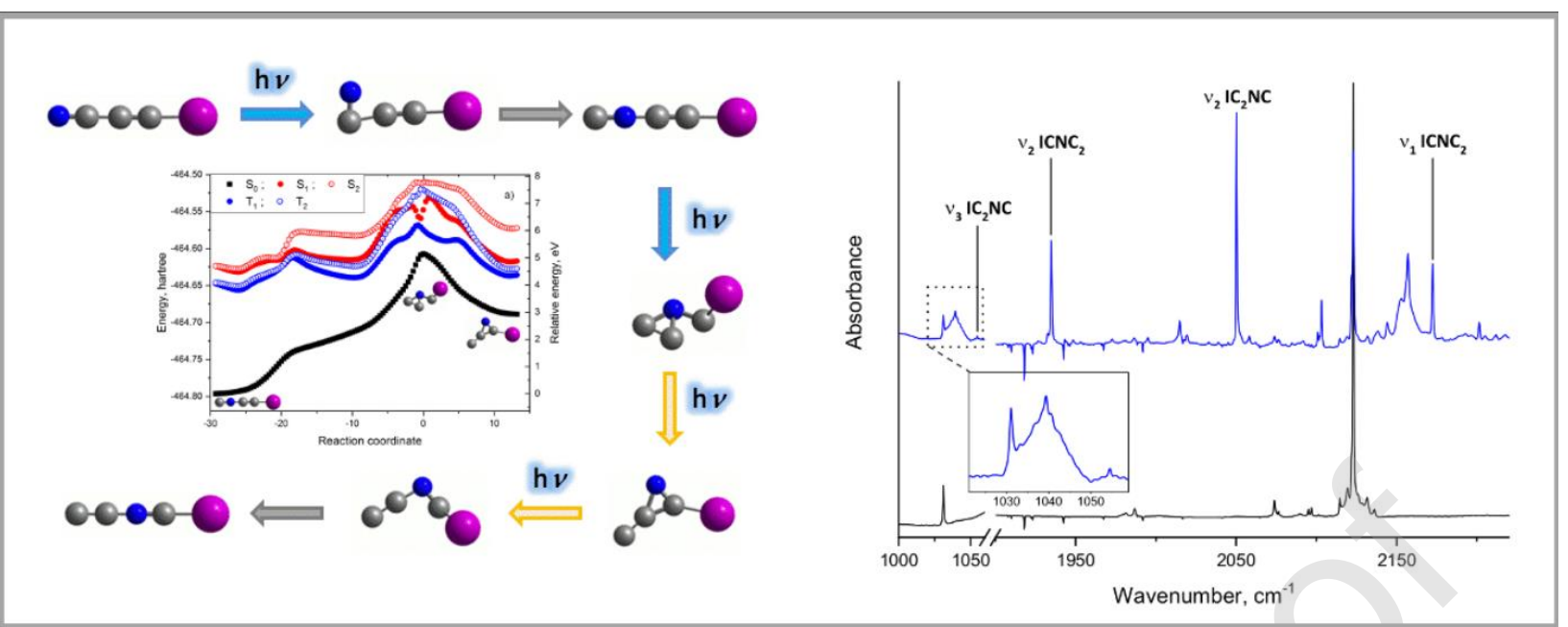

\section{Highlights}

- VUV photolysis of $\mathrm{IC}_{3} \mathrm{~N}$ in argon matrix leads to $\mathrm{IC}_{2} \mathrm{NC}$ and $I C \mathrm{ICC}_{2}$ isomers

- IRC calculations show reaction paths leading to discovered isomers

- $\mathrm{IC}_{3} \mathrm{~N}$ ions and radical are not formed in detectable amounts for the IR absorption

ABSTRACT: Here we present the results of a joint spectroscopic and quantum chemical study on the photochemistry of 3-iodo-2-propynenitrile (iodocyanoacetylene, $\mathrm{IC}_{3} \mathrm{~N}$ ). Vacuum-UV photolysis of the compound isolated in solid argon was explored. Calculations, carried out at the DFT and/or coupled-cluster level of theory, provided essential data concerning the thermodynamic stabilities, vibrational and electronic energy levels, ionization potentials, and electron affinities of $\mathrm{IC}_{3} \mathrm{~N}$-stoichiometry isomers and ions. The photochemical formation of thus far unknown species $\mathrm{IC}_{2} \mathrm{NC}$ and $\mathrm{ICNC}_{2}$ has been evidenced by the experiment and rationalized based on a detailed theoretical approach, involving the excited-state potential energy surfaces.

KEYWORDS: photochemistry, cyanoacetylenes, matrix isolation, IR spectroscopy, computational chemistry

\section{Introduction}

The direct motivation for this study stems from a larger project devoted to the photochemistry of small alkynylcarbonitriles. In particular, former investigations on 
cryogenically isolated, $\mathrm{UV}$-irradiated $\mathrm{HC}_{3} \mathrm{~N}$ and $\mathrm{HC}_{5} \mathrm{~N}$ have shown the wealth of photoproduced isomers, some of which being highly energetic and feature unusual chemical bonding. ${ }^{1-3}$ Isomerization could be anticipated also for $\mathrm{IC}_{3} \mathrm{~N}$. Moreover, it was of interest to check whether photolyzed $\mathrm{IC}_{3} \mathrm{~N}$ could be an efficient source of $\mathrm{C}_{3} \mathrm{~N}^{-}$, opening the way towards better characterization of this anion $\left(\mathrm{HC}_{3} \mathrm{~N}\right.$ and $\mathrm{HC}_{5} \mathrm{~N}$ photolyses yielded $\mathrm{C}_{3} \mathrm{~N}^{-}$and $\mathrm{C}_{5} \mathrm{~N}^{-}$, respectively, but in small amounts).

Kloster-Jensen et al. published on the location of IR and UV absorption bands of $\mathrm{IC}_{3} \mathrm{~N},{ }^{4}$ as well as on the electric dipole moment (4.59 D) of this nitrile, inferred from microwave spectra. Its Raman spectroscopy has also been studied. ${ }^{5,6}$ Linearity of the molecule was confirmed with Xray diffraction measurements. ${ }^{7}$ Bieri et al. and Kuhn et al. measured the photoelectron spectra. ${ }^{8,9}$ To our knowledge, no photochemical studies of $\mathrm{IC}_{3} \mathrm{~N}$ have ever been reported.

\section{Experimental and computational methods}

$\mathrm{IC}_{3} \mathrm{~N}$ was synthesized on a preparative scale by the method of Kloster-Jensen, involving the reaction of $\mathrm{HC}_{3} \mathrm{~N}$ with $\mathrm{I}_{2} / \mathrm{KI}$ alkaline solution. ${ }^{4}$ The product was characterized by ${ }^{13} \mathrm{C} \mathrm{NMR}$ spectroscopy: ${ }^{13} \mathrm{C}$ NMR $\left(\left(\mathrm{CD}_{3}\right)_{2} \mathrm{CO}, 100 \mathrm{MHz}\right) \delta 22.4$ (s, C-I), 67.8 (s, C-CN); 106.1 (s, CN). The chemical shift of the sp carbon next to the iodine atom, observed at high-field, is characteristic of iodoalkynes. Traces of $\mathrm{HC}_{3} \mathrm{~N}$ could not be completely removed by freeze-pumpthaw cycles.

Gaseous $\mathrm{IC}_{3} \mathrm{~N}$ was mixed with $\operatorname{Ar}$ (Multax s.c.) in ratios ranging from 1:600 to 1:1100, in a vacuum manifold equipped with capacitance manometers (MKS Instruments). Mixtures were deposited at a rate of about $2 \mathrm{mmol} / \mathrm{h}$ onto a CsI substrate window, the latter attached to the cold finger of an Air Products Displex DE-202S cryostat. In photochemical experiments, the window was continuously VUV-irradiated (see below) throughout the sample deposition. The window was held either at $15-17 \mathrm{~K}$ or, exclusively during VUV irradiations, at $19 \mathrm{~K}$. For electronic spectroscopy measurements, gaseous $\mathrm{IC}_{3} \mathrm{~N}$ ( 0.13 Torr at room temperature) was mixed with 100 Torr of argon in a 10-cm glass cuvette equipped with quartz windows. Spectra were recorded in the $205-700 \mathrm{~nm}$ range with a resolution of $1.0 \mathrm{~nm}$, using a Shimadzu UV-3100 instrument. A Nicolet Magna 560 FTIR spectrometer was used for IR absorption measurements in the 4000 $400 \mathrm{~cm}^{-1}$ range with a resolution of $0.5 \mathrm{~cm}^{-1}$. 
For far-UV photolysis experiments, a microwave-driven $\mathrm{Kr}$ discharge lamp (Opthos Instrument Comp.) was attached to the vacuum shroud of the cryostat, about $5 \mathrm{~cm}$ from the sample substrate. The lamp, operated at $20 \mathrm{~W}$, had a broadband spectral characteristic (127-160 $\mathrm{nm}$ ) with a maximum near $145 \mathrm{~nm}$; the emitted beam was not focused. The slightly elevated deposition temperature $(19 \mathrm{~K})$ was applied to boost the photochemical processes.

The Becke's three-parameter hybrid exchange functional including the correlation functional of Lee, Yang, and Parr (B3LYP) was selected for the majority of DFT calculations. ${ }^{10}$ 11 The Dunning's correlation-consistent polarized valence triple-zeta basis set, ${ }^{12}$ augmented by s, $\mathrm{p}, \mathrm{d}$, and f functions (aug-cc-pVTZ) was used for $\mathrm{N}$ and $\mathrm{C}$, while for the I atom a basis set with pseudopotentials (hereafter: PP) was employed. ${ }^{13}$ Geometric structures, energies, and harmonic frequencies were calculated for $\mathrm{IC}_{3} \mathrm{~N}$, its isomers, and several other potential photolysis products. The harmonic frequencies were scaled with a factor of 0.96 to correct for anharmonicity and for other inherent deficiencies of the DFT approach. ${ }^{14,15}$ Transition states were localized on the electronic ground state potential energy surface (PES) using the Berny algorithm. ${ }^{16}$ Their nature was verified by inspection of vibrational frequencies (exactly one imaginary frequency was expected). Further IRC (intrinsic reaction coordinate) calculations indicated the geometries of species linked by a given transition state. ${ }^{17}$ In order to describe the mechanism of a photo-induced reaction, knowledge of excited PESs is crucial. Both triplet and singlet excited electronic state energies were calculated using the time-dependent DFT (TDDFT) version. ${ }^{18-20}$ The Tamm-Dancoff approximation was applied, as it was reported to perform well for numerically unstable cases and was found to provide reliable singlet-triplet separations. ${ }^{21-25}$ Excited-state PES landscapes were approximated using vertical excitations for a series of geometries obtained with ground-state IRC calculations.

The geometries of selected lowest excited states of $\mathrm{IC}_{3} \mathrm{~N}$ and $\mathrm{IC}_{2} \mathrm{NC}$ were optimized with the B3PW91 functional and the same basis sets as for the ground state. B3PW91 (differing from B3LYP by a PW91 non-local correlation term $)^{26-28}$ has already been successfully used to describe some excited electronic states of cyanoacetylene family molecules, including $\mathrm{HC}_{9} \mathrm{~N},{ }^{29}$ $\mathrm{CH}_{3}-\mathrm{C}_{3} \mathrm{~N},{ }^{30}$ and $\mathrm{CH}_{3}-\mathrm{C}_{5} \mathrm{~N} .{ }^{31}$ We verified the reliability of B3PW91-derived vertical excitation energies by applying also the CAM-B3LYP functional ${ }^{32}$ with large basis sets (aug-cc-pVQZ for $\mathrm{C}$ and N, and aug-cc-pVQZ-PP for the I atom). ${ }^{12,33}$ 
Second order perturbation theory (VPT2) was used to predict anharmonic vibrational frequencies and intensities for fundamental, ${ }^{34-36}$ overtone, and combination bands, at the B3LYP level of theory. All DFT calculations were carried out using the Gaussian 09 Rev. E. 01 set of programs..$^{37}$ The vibrational self-consistent field (VSCF) ${ }^{38,39}$ and correlation-corrected vibrational self-consistent field (VMP2) ) $^{39,40}$ methods were also used to compute anharmonic fundamental frequencies using a frozen-core version of $\operatorname{CCSD}(\mathrm{T})$ (coupled-cluster singles and doubles with perturbative treatment of triples). ${ }^{41-46}$ These two different approaches, VSCF and VMP2, were chosen to check for consistency of the resulting frequencies (variational VSCF computations are not as sensitive to resonance-related artifacts as those carried out with the perturbation methods VMP2 and VPT2. An efficient approach was used in VSCF and VMP2 calculations to generate potential energy surfaces around the equilibrium structures. ${ }^{47-49}$ Fundamental harmonic frequencies were numerically derived, ${ }^{50,51}$ for the previously optimized ${ }^{52}$ structures. One- and two-body terms were included. For CCSD(T) computations, Dunning's correlation-consistent polarized valence triple-zeta basis set (cc-pVTZ) ${ }^{12}$ was selected for N and $\mathrm{C}$, while a basis set with pseudopotentials (cc-pVTZ-PP) ${ }^{13}$ was used for the I atom. All ab initio calculations of anharmonic vibrational frequencies were performed with the Molpro 2012.1 software. ${ }^{53,54}$ Computational results were visualized using ChemCraft. ${ }^{55}$

\section{Results and discussion}

\section{Electronic spectroscopy}

Table 1 contains vertical electronic excitation energies and the respective oscillator strengths computed by CAM-B3LYP/aug-cc-pVQZ for $\mathrm{IC}_{3} \mathrm{~N}$. Optimization of excited-state structures starting from a linear geometry using B3PW91/aug-cc-pVTZ failed for most states or led to imaginary frequencies. This suggested a non-linearity of these states. Indeed, our search for the equilibrium geometry of the lowest excited singlet $\left(\mathrm{S}_{1}\right)$ and triplet $\left(\mathrm{T}_{1}\right)$ revealed the bent structures (Figs. S1 and S2). Similar computations were performed for $\mathrm{IC}_{2} \mathrm{NC}$, a likely photochemical product arising from UV irradiation of $\mathrm{IC}_{3} \mathrm{~N}$ (see Table S1 and Figs. S1-S2 of the Supplementary material). The predicted $0-0$ (i.e. vibrationless) energies of $\mathrm{S}_{1}-\mathrm{S}_{0}$ excitations are $3.3 \mathrm{eV}$ and $3.2 \mathrm{eV}$ (TD-B3PW91/aug-cc-pVTZ) for $\mathrm{IC}_{3} \mathrm{~N}$ and $\mathrm{IC}_{2} \mathrm{NC}$, respectively. 
A UV-Vis spectrum of gaseous $\mathrm{IC}_{3} \mathrm{~N}$ is presented in Fig. 1. The molecule is a strong absorber. One can discern a structure resembling that previously reported, namely the bands at 222, 233, 245 and $262 \mathrm{~nm}$, measured by Kloster-Jensen et al. in a cyclohexane solution. ${ }^{56}$ The band pattern is similar to the one known for $\mathrm{HC}_{3} \mathrm{~N},{ }^{57-59}$ but $\mathrm{IC}_{3} \mathrm{~N}$ bands are distinctly broader. ${ }^{30}$ The spectrum shows clear maxima at 44 400, 41 400, 39 300, and 36600 and $\mathrm{cm}^{-1}(225,242,254$, and 273). According to the predictions of Table 1, there are three closely spaced electronic states around $250 \mathrm{~nm}$. While at least one of these is responsible for the said (presumably vibronic) bands, no reliable assignments can currently be proposed.

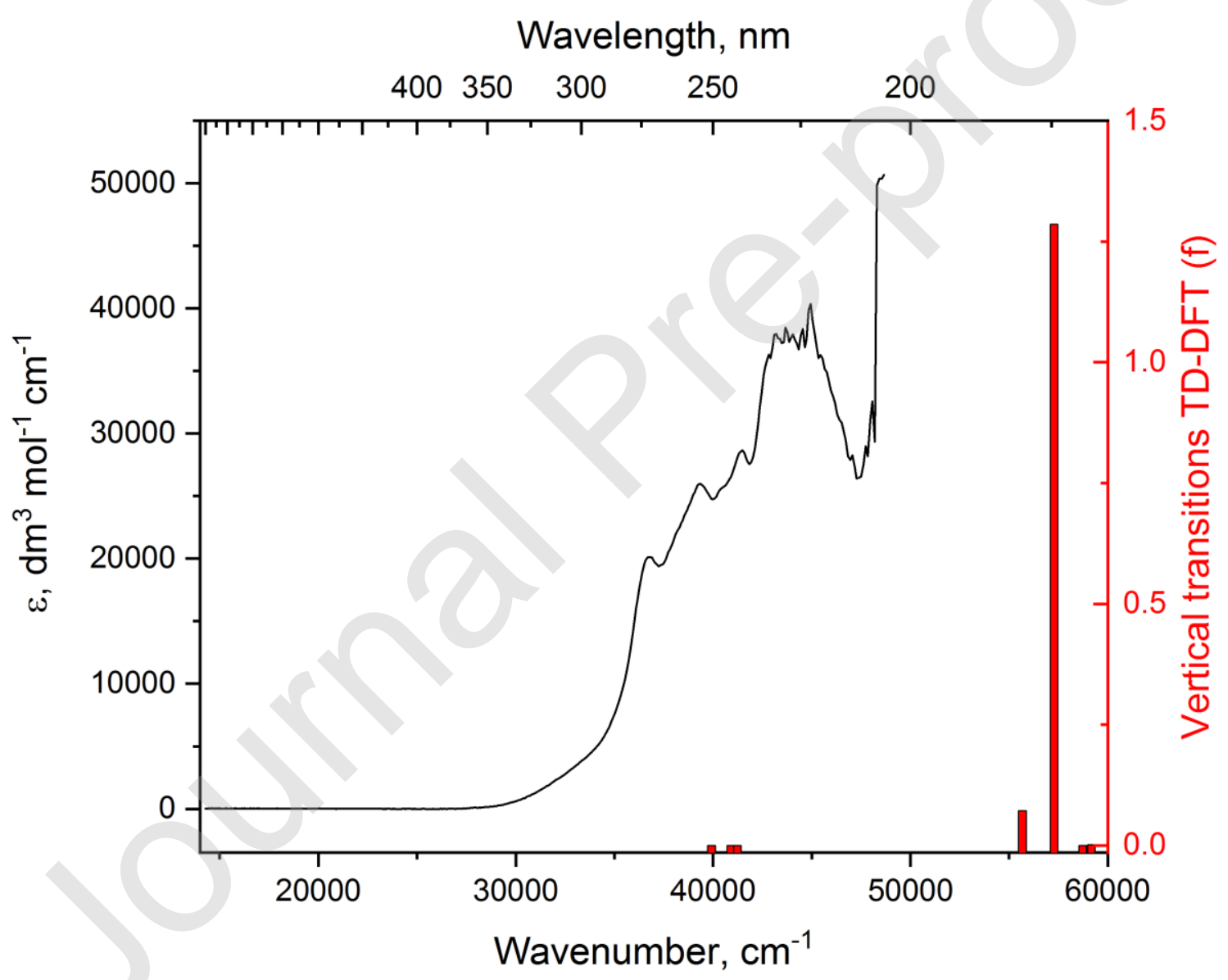

Figure 1. UV-Vis absorption spectrum of $\mathrm{IC}_{3} \mathrm{~N}$, as measured for a gas-phase sample. Bars indicate the predicted location and oscillator strength of vertical electronic transitions, derived with TD-CAM-B3LYP/aug-cc-pVQZ. 


\section{IR spectroscopy}

An IR absorption spectrum of $\mathrm{IC}_{3} \mathrm{~N}$ in Ar obtained for a sample deposited without photolysis (see Fig. 2) served as a reference for comparison with a photo-processed matrix. Fundamental vibrational bands have been identified based on data published (Table 2). ${ }^{6,60}$ A high $\mathrm{S} / \mathrm{N}$ ratio allowed assignment of new combination bands and of several spectral features belonging to ${ }^{13} \mathrm{C}$ and ${ }^{15} \mathrm{~N}$ isotopologues of $\mathrm{IC}_{3} \mathrm{~N}$ present at their natural abundance (see Tables $\mathrm{S} 2-\mathrm{S} 3$ and the insets of Fig. 2); this was assisted with DFT predictions of isotopic shifts. Furthermore, it was possible to identify, for the first time, various combination and overtone vibrational bands of the molecule (Table 2). Several weak, unassigned bands may either be due to more complicated combinations of $\mathrm{IC}_{3} \mathrm{~N}$ vibrational modes or to impurities.

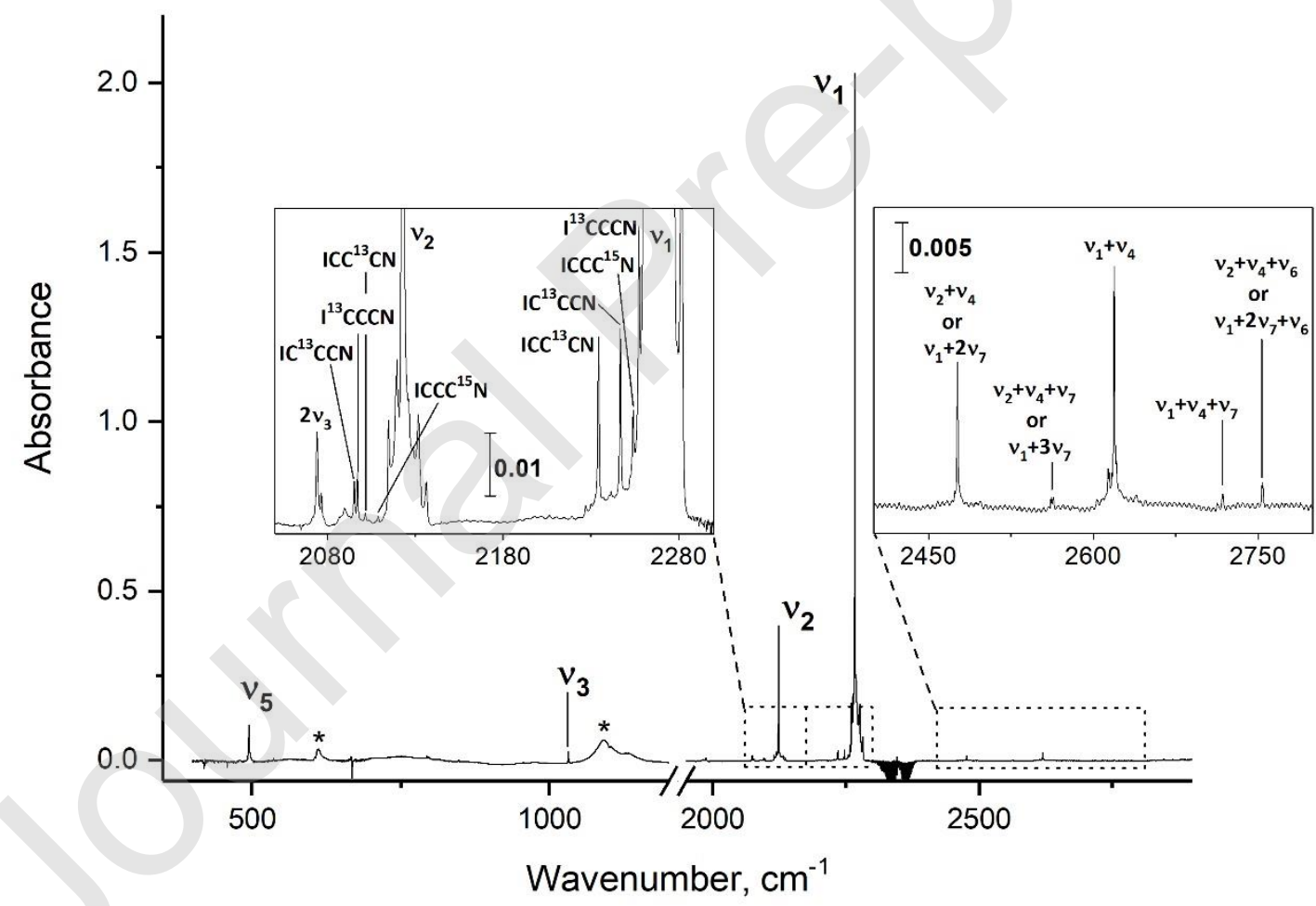

Figure 2. IR absorption spectrum of $\mathrm{IC}_{3} \mathrm{~N}$ in solid $\mathrm{Ar}$ at $15 \mathrm{~K}$. Asterisked bands arise from incomplete compensation of CsI substrate absorption. 


\section{Theoretically considered $I_{3} N$ photolysis products}

$\mathrm{IC}_{3} \mathrm{~N}$ is a halogenated analogue of the extensively studied molecule $\mathrm{HC}_{3} \mathrm{~N}$. UV irradiation of the latter in inert cryogenic matrixes leads to $\mathrm{HCCNC}, \mathrm{HCNCC}$, and CCCNH. ${ }^{1,62-64}$ We computed the electronic energies, structures, and vibrational IR absorption parameters of the 3 analogous isomers bearing iodine in place of hydrogen (Fig. 3). The ensuing relative energy values and molecular geometries turn out to be similar to those characterizing the $\mathrm{HC}_{3} \mathrm{~N}$ family of isomers. The most stable is the nitrile $\mathrm{IC}_{3} \mathrm{~N}$, the isonitrile $\mathrm{IC}_{2} \mathrm{NC}$ being more energetic by about 137 $\mathrm{kJ} / \mathrm{mol}$. Much less stable are two other chain structures: $\mathrm{C}_{3} \mathrm{NI}$ and $\mathrm{C}_{2} \mathrm{NCI}$. No bound $\mathrm{Y}$-shaped carbene structure $\mathrm{C}_{2}(\mathrm{I}) \mathrm{CN}$, analogous to the cyanovinylidene molecule, ${ }^{65-67}$ has been found in our B3LYP study, but CAM-B3LYP computations suggest the presence of a corresponding shallow potential energy minimum. IR spectroscopic parameters predicted for the lowest-energy $\mathrm{IC}_{3} \mathrm{~N}$ molecules can be found further in the text and in the Tables $\mathrm{S} 3-\mathrm{S} 5$ of the Supplementary material.

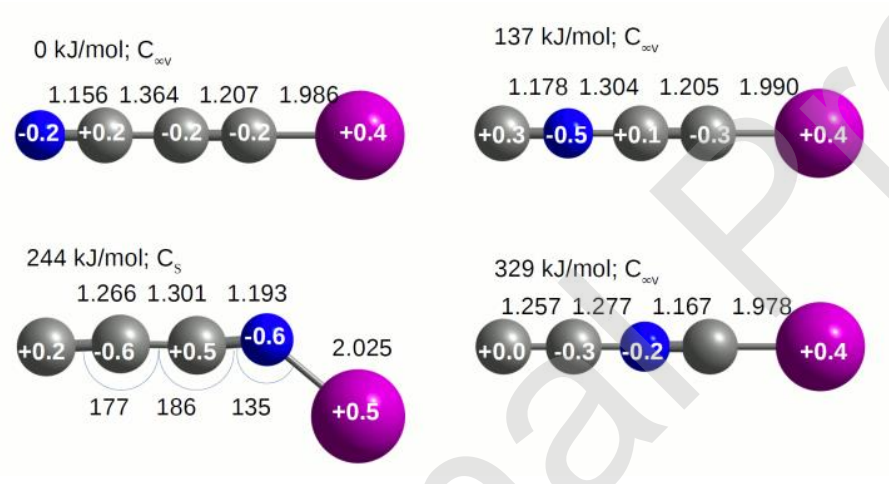

Figure 3. Relative ZPE-corrected electronic energies and structures ( $\AA$, deg) of the selected $\mathrm{IC}_{3} \mathrm{~N}$ isomers (NBO charges are given for each atom), as derived with B3LYP/aug-cepVTZ (aug-cc-pVTZ-PP for I atom). See Table S5 for the computed ionization energy and electron affinity values.

Table S5 of the Supplementary material presents ionization energies predicted for the four considered isomeric variants of $\mathrm{IC}_{3} \mathrm{~N}$. What follows from these results is that none of the respective cations should be expected to appear out of $\mathrm{IC}_{3} \mathrm{~N}$ irradiated with the presently applied far-UV lamp $(\lambda>127 \mathrm{~nm})$. Neither was any obvious source of electrons, leading to the corresponding anions, available in our experiment. Nevertheless, Table S5 provides also the 
electron affinities, as these, together with the structural parameters given in Fig. S3, might be useful in the interpretation of future experiments. The calculated ionization energy of $\mathrm{IC}_{3} \mathrm{~N}$ ( 989 $\mathrm{kJ} / \mathrm{mol})$ is a good match to the value found experimentally, i.e. $974.5 \mathrm{~kJ} / \mathrm{mol}(10.1 \mathrm{eV}$ or 123 nm). ${ }^{9}$

Our theoretical treatment of permanent dissociation processes was limited here to the consideration of net thermodynamic effects confined to the ground-state potential energy surface. Reaction endothermicities were compared to the amount of supplied energy (equivalent to $\lambda>$ $127 \mathrm{~nm}$ ). What follows is that one cannot rule out the dissociation of $\mathrm{IC}_{3} \mathrm{~N}$ into either $\mathrm{I}+\mathrm{C}_{3} \mathrm{~N}$, $\mathrm{ICN}+\mathrm{C}_{2}$ or $\mathrm{IC}_{2}+\mathrm{CN}$, while the heterolytic formation of ionic pairs, e.g. $\mathrm{I}^{+}+\mathrm{C}_{3} \mathrm{~N}^{-}$, is not likely (Table S6). This simplistic approach does not allow us to conclude on the actual feasibility of the said homolytic cleavages, as it neglects the involvement of excited electronic states, possible energy barriers, and, of importance in cryogenic matrices, the cage effect. ${ }^{68}$ The latter often curbs any durable separation of photofragments, giving preference to the stoichiometry-preserving molecular rearrangements.

Additionally, the possible formation of noble gas compounds $\mathrm{IArC}_{3} \mathrm{~N}$ and $\mathrm{IC}_{2} \mathrm{ArCN}$ has been computationally examined. The respective theoretical predictions are provided in Fig. S4 and Table S7 of Supplementary materials (present experiments gave no supportive evidence for these species).

\section{Photolysis results and discussion}

Far-UV photolysis of Ar matrix-isolated $\mathrm{IC}_{3} \mathrm{~N}$ led to the appearance of new bands in the IR absorption spectrum (see Fig. 4). The evolution of these was monitored over the course of the experiment. Thermal cycling (annealing) steps, involving the sample warm-up to approx. $22 \mathrm{~K}$ for about 6 minutes, followed by re-cooling to $15 \mathrm{~K}$, was performed after the irradiation. 


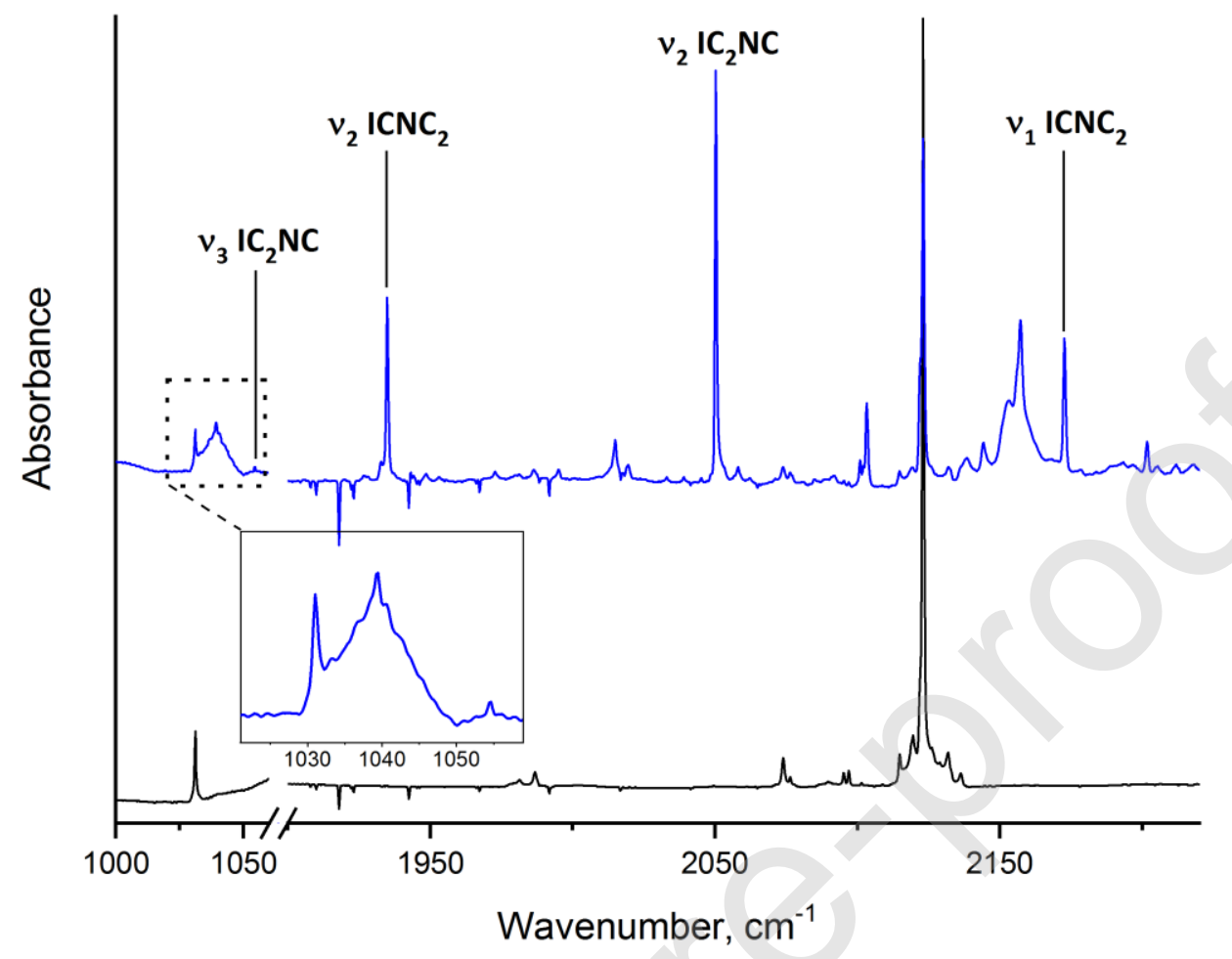

Figure 4. Bands of isomers in the IR absorption spectrum of VUV-photolyzed $(\lambda>127 \mathbf{n m})$ $\mathrm{IC}_{3} \mathrm{~N}$ isolated in solid Ar (upper trace). Bottom trace shows the spectrum of a nonirradiated sample. Absorbance scales are arbitrary.

In the case of $\mathrm{IC}_{3} \mathrm{~N}$, the observed IR band intensity pattern was correctly reproduced by our DFT calculations (see Table 2). We assume a similar reliability of this theoretical approach applied to other closed-shell $\mathrm{IC}_{3} \mathrm{~N}$-stoichiometry species.

Data gathered in Table 3 concern the identification of $\mathrm{IC}_{2} \mathrm{NC}$. A prominent IR absorption feature at $2050.2 \mathrm{~cm}^{-1}$ can be identified as $v_{2}$. It is predicted for this isomer as the strongest one. The second strongest band, the one due to $v_{6}$ bending, is expected at around $270 \mathrm{~cm}^{-1}$, well beyond our available spectral range. The $v_{3}$ stretching is predicted as 2 orders of magnitude less intense in IR than $v_{2}$. Band strength data, collected throughout the photolysis, were helpful in the search for this weak feature. Correlations of integrated intensities, involving the postulated $v_{2}$ band and 
the $v_{3}$ candidate bands at $1054.5 \mathrm{~cm}^{-1}$ (Fig. 5a) and $1039.5 \mathrm{~cm}^{-1}$ (Fig. 5b) were analyzed. Considering the extent of error bars, Fig. 5a shows (unlike Fig. 5b) quite a probable linear correlation. Common origin of the spectral features located at $2050.2 \mathrm{~cm}^{-1}$ and $1054.5 \mathrm{~cm}^{-1}$ is additionally suggested by their similar resistance to annealing (in contrast to the $1039.5 \mathrm{~cm}^{-1}$ band, slightly decreasing upon thermal treatment). Noteworthy, a broad hump centered at 1040 $\mathrm{cm}^{-1}$ is much too strong to be due to the $v_{3}$ mode; its integrated intensity is almost the same as for the $2050.2 \mathrm{~cm}^{-1}$ band. In view of the above considerations, the sharp $1054.5 \mathrm{~cm}^{-1}$ feature is interpreted here as the $v_{3}$ band of $\mathrm{IC}_{2} \mathrm{NC}$. 

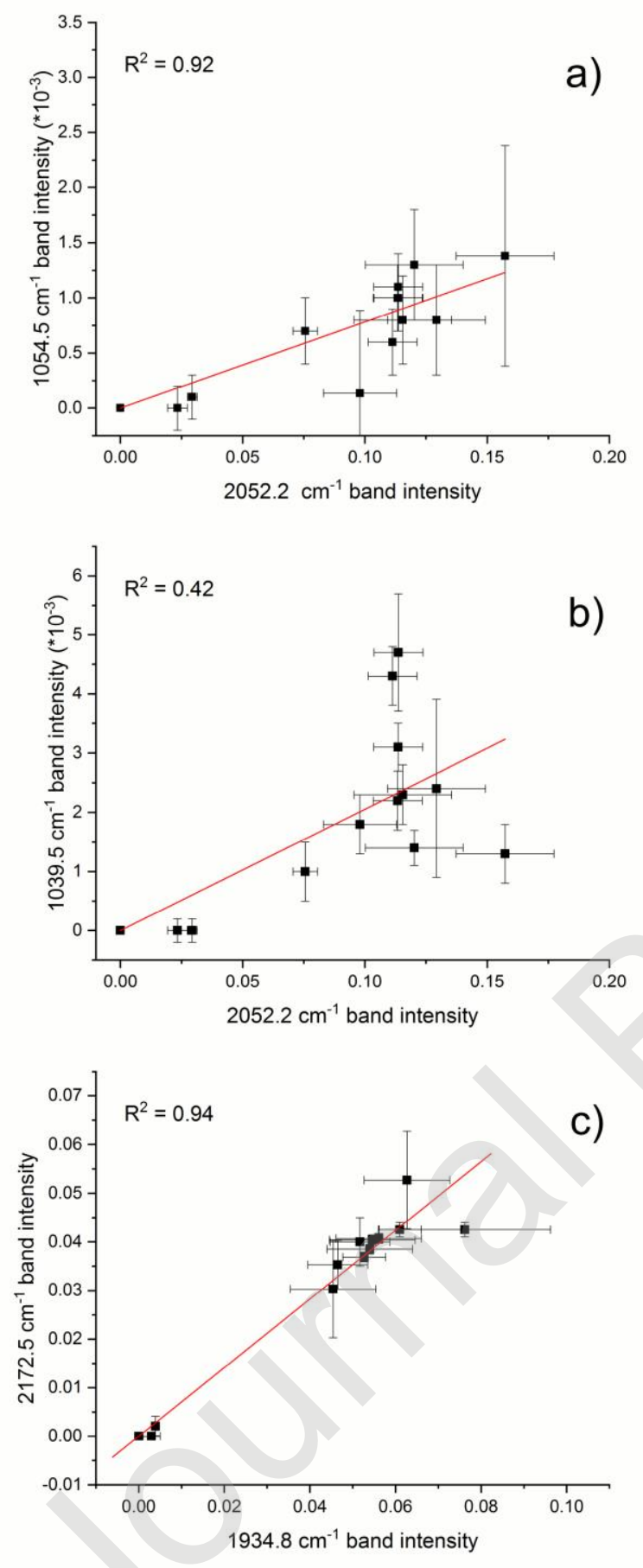

Figure 5. Correlation of the measured integrated optical density values for selected pairs of IR bands relevant to the identification of $\operatorname{IC}_{2} \mathrm{NC}(a, b)$ and $\operatorname{ICNC}_{2}(c)$, arising in the course of far-UV photolysis of $\mathrm{IC}_{3} \mathrm{~N}$ isolated in solid argon. Red lines represent leastsquares linear fits. 
The predicted frequency of the $v_{5}$ bending vibration of $\mathrm{IC}_{2} \mathrm{NC}$ formally falls within the spectral range of the instrument used, although a $\mathrm{S} / \mathrm{N}$ decrease near $400 \mathrm{~cm}^{-1}$ prevented detection of the respective absorption. On the other hand, the IR spectrum is crowded with absorption features around the predicted $\mathrm{IC}_{2} \mathrm{NC} v_{1}$ frequency. The anticipated separation of $v_{1}$ and $v_{2}$ is about 200 $\mathrm{cm}^{-1}$ at DFT and $220 \mathrm{~cm}^{-1}$ at $\operatorname{CCSD}(\mathrm{T})$ levels of theory. One can therefore expect to find the $v_{1}$ band of $\mathrm{IC}_{2} \mathrm{NC}$ at around $2260 \pm 20 \mathrm{~cm}^{-1}$. Theory describes it as even weaker than $v_{3}$, and comparable in intensity to the bands of ${ }^{13} \mathrm{C}$-isotopomers of the parent species, located in the same region (cf. Fig. 2). Without further studies, involving isotopically labeled precursor species or the application of Raman spectroscopy (indeed, the expected Raman activity and IR absorption intensity patterns significantly differ one from the other; see Table 3), it is impossible to assign any specific band to the $v_{1}$ mode of $\mathrm{IC}_{2} \mathrm{NC}$.

We have carried out a theoretical study on the $\mathrm{IC}_{3} \mathrm{~N} \rightarrow \mathrm{IC}_{2} \mathrm{NC}$ reaction, starting from the groundstate rearrangement, analyzed within the IRC scheme. Energies of the lowest excited singlet and triplet states were derived assuming vertical excitations from discreet IRC-obtained ground-state structures along the reaction coordinate. The result is depicted in Fig. 6. The computed groundstate activation energy (including zero-point energy contributions) amounts to $267 \mathrm{~kJ} / \mathrm{mol}$, a value similar to that reported for the analogous isomerization of $\mathrm{HC}_{3} \mathrm{~N}(272 \mathrm{~kJ} / \mathrm{mol}) .{ }^{69} \mathrm{This}$ is well below the energies of any excited electronic state of $\mathrm{IC}_{3} \mathrm{~N}$. When the parent molecule absorbs a vacuum-UV photon from a $\mathrm{Kr}$ lamp, the reaction may proceed by overcoming the barrier in an excited singlet state, with a possible crossing to the lowest triplet-state surface. 


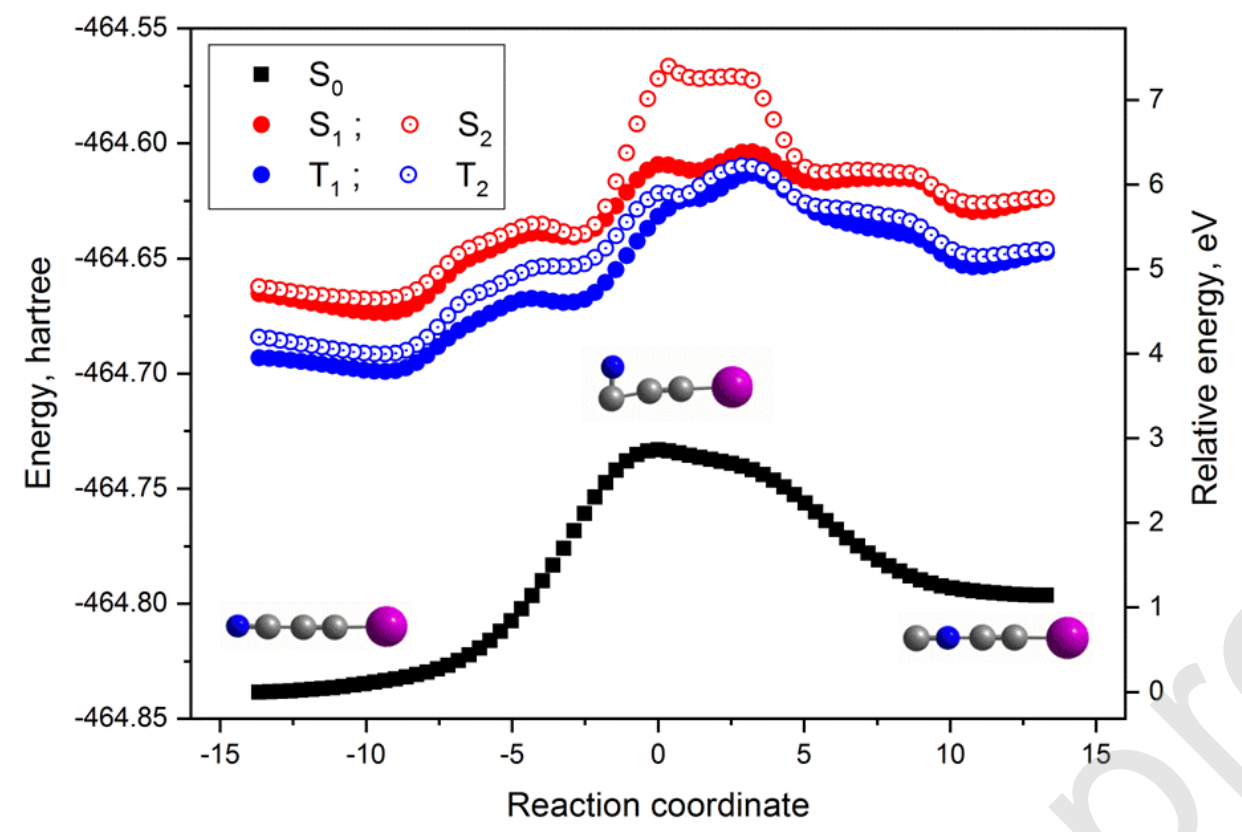

Figure 6. Ground- and selected excited-state cross-sections of $\mathrm{IC}_{3} \mathrm{~N}$ potential energy surfaces depicting the isomerization towards $\mathrm{IC}_{2} \mathrm{NC}$. The reaction coordinate comes from ground-state IRC calculations at the B3LYP/aug-cc-pVTZ (aug-cc-pVTZ-PP for I atom) level of theory. Molecular geometries corresponding to the two energy minima and a transition state are shown. Excited state energies were derived by TD-DFT calculations, departing from the respective ground-state geometries.

As demonstrated in Fig. 5c, spectral features observed at $2172.5 \mathrm{~cm}^{-1}$ and $1934.8 \mathrm{~cm}^{-1}$ are well correlated throughout the photolysis time. It was at first tempting to consider the $\mathrm{C}_{3} \mathrm{~N}^{-}$anion as their possible common carrier. However, rather than a single $2172.5 \mathrm{~cm}^{-1}$ feature, the reported spectrum of $\mathrm{C}_{3} \mathrm{~N}^{-}$coming from $\mathrm{HC}_{3} \mathrm{~N}$ photolysis in solid Ar revealed a Fermi-resonance doublet manifesting as two bands located at 2173.0 and $2178.0 \mathrm{~cm}^{-1} \cdot{ }^{70,71}$ Secondly, a mismatch of about $10 \mathrm{~cm}^{-1}$ between $1934.8 \mathrm{~cm}^{-1}$ and the frequency of another $\mathrm{HC}_{3} \mathrm{~N}$-derived anion band, 1944.0 $\mathrm{cm}^{-1}$, is large, even considering some differences in local microenvironments (matrix cages) inherent to $\mathrm{IC}_{3} \mathrm{~N}$ and $\mathrm{HC}_{3} \mathrm{~N}$ experiments. Finally, the intensity ratio of $2172.5 \mathrm{~cm}^{-1}$ and 1934.8 $\mathrm{cm}^{-1}$ bands differs greatly from that reported for the two strongest $\mathrm{C}_{3} \mathrm{~N}^{-}$IR absorption features produced upon the photolysis of $\mathrm{HC}_{3} \mathrm{~N}$. The currently observed ratio matches decently, however, what is predicted for the $\mathrm{ICNC}_{2}$ isomer, as do the frequencies of the two bands (see Table 4). In 
view of the above, and considering that a similar rearrangement, $\mathrm{HC}_{3} \mathrm{~N} \rightarrow \mathrm{HCNC}_{2}$, has been observed for cyanoacetylene, we assign the said bands to $\mathrm{ICNC}_{2}$.

According to our computations, UV photons available in this experiment are energetic enough (their spectrum extending from $9.76 \mathrm{eV}$ to near-IR) to overcome all energy barriers separating $\mathrm{IC}_{3} \mathrm{~N}$ from $\mathrm{ICNC}_{2}$. The initial step most likely involves $\mathrm{IC}_{3} \mathrm{~N} \rightarrow \mathrm{IC}_{2} \mathrm{NC}$ isomerization, described above (Fig. 6). The path then proceeds (Fig. 7a) via a cyclic isomer. The latter species appears with a large excess of energy, which likely facilitates an efficient conversion towards $\mathrm{ICNC}_{2}$ (Fig. 7b). While the exact identity of the involved potential energy surfaces is not known, the path may lead either through singlet or triplet states of the participating molecules. 

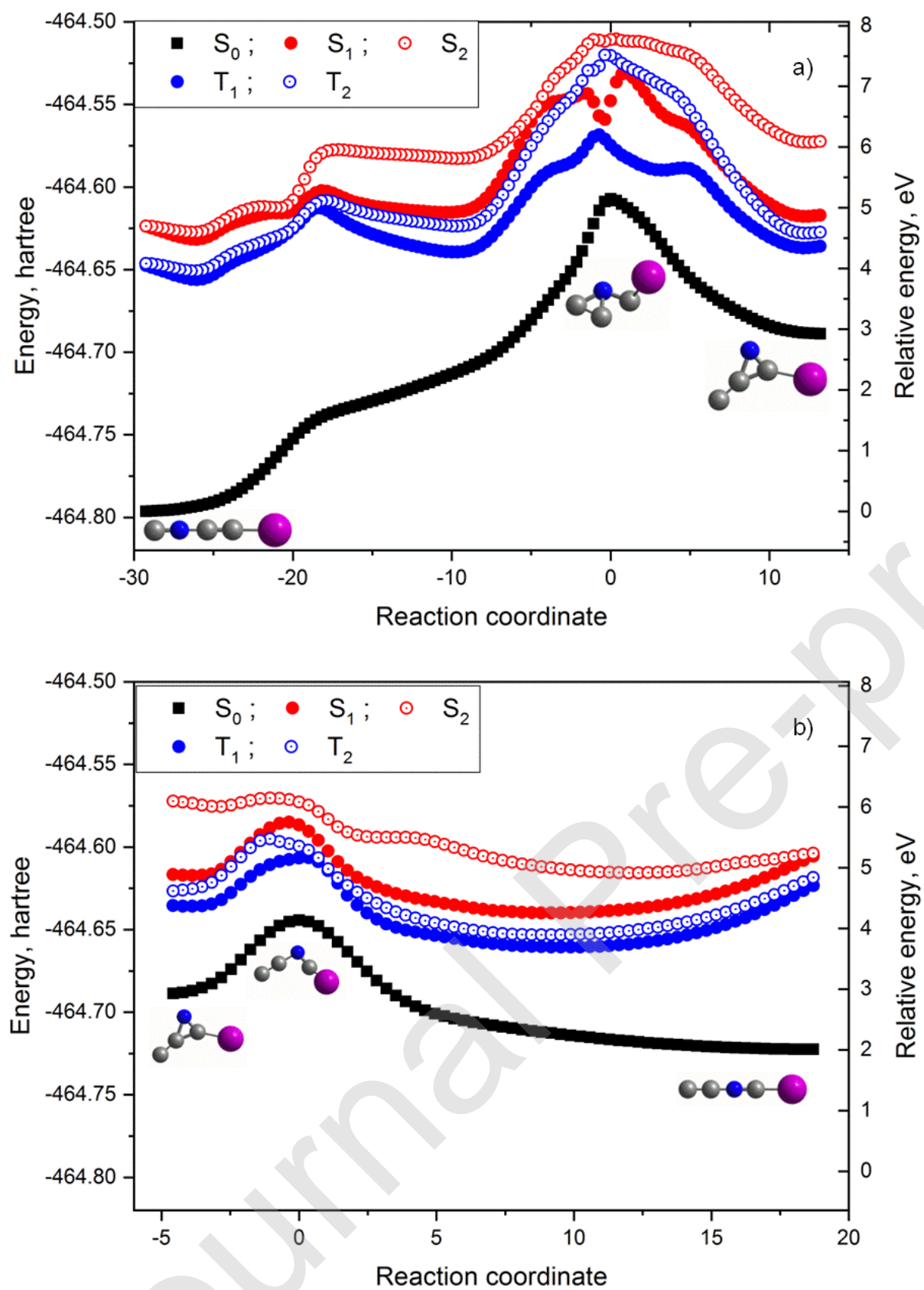

Figure 7. Ground- and selected excited-state cross-sections of $\mathrm{IC}_{3} \mathrm{~N}$ potential energy surfaces depicting a 2-step (panels $a$ and $b$ ) isomerization path from $\mathrm{IC}_{2} \mathrm{NC}$ to ICNC2. The reaction coordinate comes from ground-state IRC calculations at the B3LYP/aug-cc-pVTZ (aug-cc-pVTZ-PP for I atom) level of theory. Molecular geometries corresponding to the energy minima and transition states are shown. Excited state energies were derived by TDDFT calculations departing from the respective ground-state geometries. 


\section{Conclusions}

There is experimental evidence, backed with theoretical predictions, for the formation of chain species $\mathrm{IC}_{2} \mathrm{NC}$ and $\mathrm{ICNC}_{2}$ upon far-UV photolysis of iodocyanoacetylene isolated in solid argon. The two isomeric species have not, to our knowledge, been observed before. IR-spectroscopic description of the parent $\mathrm{IC}_{3} \mathrm{~N}$ molecule has been appended with the assignment of additional combination bands. Several fundamental IR transitions of ${ }^{13} \mathrm{C}$ - and ${ }^{15} \mathrm{~N}$-isotopologues of $\mathrm{IC}_{3} \mathrm{~N}$, present in their natural abundances, were identified. No $\mathrm{IC}_{3} \mathrm{~N}$-related ions, in particular no $\mathrm{C}_{3} \mathrm{~N}^{-}$, have been detected in the course of these experiments.

\section{Declaration of interests}

The authors declare that they have no known competing financial interests or personal relationships that could have appeared to influence the work reported in this paper.

\section{Acknowledgments}

J.-C.G. thanks the Program PCMI (INSU-CNRS) and the Centre National d'Etudes Spatiales (CNES) for funding. Authors wish to thank Thomas Custer for valuable suggestions and comments on the manuscript. 


\section{References}

(1) Kołos, R.; Waluk, J. Matrix-Isolated Products of Cyanoacetylene Dissociation. J. Mol. Struct. 1997, 408-409, 473-476. https://doi.org/10.1016/S0022-2860(96)09573-7.

(2) Coupeaud, A.; Kołos, R.; Couturier-Tamburelli, I.; Aycard, J. P.; Piétri, N. Photochemical Synthesis of the Cyanodiacetylene $\mathrm{HC}_{5} \mathrm{~N}$ : A Cryogenic Matrix Experiment. J. Phys. Chem. A 2006, 110 (7), 2371-2377. https://doi.org/10.1021/jp055582r.

(3) Coupeaud, A.; Turowski, M.; Gronowski, M.; Piétri, N.; Couturier-Tamburelli, I.; Kołos, R.; Aycard, J.-P. Spectroscopy of Cyanodiacetylene in Solid Argon and the Photochemical Generation of Isocyanodiacetylene. J. Chem. Phys. 2007, 126 (16), 164301. https://doi.org/10.1063/1.2720842.

(4) Kloster-Jensen, E.; Dyrssen, D.; Johansson, L.; Norén, B.; Munch-Petersen, J. Unsaturated Hydrogen-Free Halogeno Cyano Compounds. I. Synthesis and Properties of Iodocyanoacetylene. Acta Chem. Scand. 1963, 17, 1859-1861. https://doi.org/10.3891/acta.chem.scand.17-1859.

(5) Klaboe, P.; Kloster-Jensen, E. Raman Spectra and Revised Vibrational Assignments of Some Halogeno Cyanoacetylenes. Spectrochim. Acta Part Mol. Spectrosc. 1967, 23, 1981-1990. https://doi.org/10.1016/0584-8539(67)80085-0.

(6) Nolin, C.; Weber, J.; Savoie, R. Vibrational Spectra of Crystalline HCCN, DCCCN, ClCCCN, BrCCCN, and ICCCN. J. Raman Spectrosc. 1976, 5 (1), 21-33. https://doi.org/10.1002/jrs.1250050104.

(7) Borgen, B.; Hassel, O.; Römming, Chr.; Block-Bolten, A.; Toguri, J. M.; Flood, H. Mutual Arrangement of Iodo-Cyano-Acetylene Molecules in the Solid. Acta Chem. Scand. 1962, 16, 2469-2470. https://doi.org/10.3891/acta.chem.scand.16-2469.

(8) Bieri, G.; Heilbronner, E.; Hornung, V.; Kloster-Jensen, E.; Maier, J. P.; Thommen, F.; Niessen, W. von. Electronic States of Substituted Haloacetylene and Cyanoacetylene Radical Cations. Chem. Phys. 1979, 36, 1-14. https://doi.org/10.1016/03010104(79)85099-5.

(9) Kuhn, R.; Maier, J. P.; Thommen, F. Photoelectron-Photon Coincidence Studies of the $\widetilde{A}$ and $\widetilde{\mathrm{B}}$ excited Electronic States of $\mathrm{X}-\mathrm{C} \equiv \mathrm{C}-\mathrm{C} \equiv \mathrm{N}^{+}, \mathrm{X}=\mathrm{CH}_{3}, \mathrm{CD}_{3}, \mathrm{Cl}, \mathrm{Br}$, I. J. Electron Spectrosc. Relat. Phenom. 1984, 34 (3), 253-260. https://doi.org/10.1016/03682048(84)80069-9. 
(10) Becke, A. D. Density-functional Thermochemistry. IV. A New Dynamical Correlation Functional and Implications for Exact-exchange Mixing. J. Chem. Phys. 1996, 104 (3), 1040-1046. https://doi.org/10.1063/1.470829.

(11) Lee, C.; Yang, W.; Parr, R. G. Development of the Colle-Salvetti Correlation-Energy Formula into a Functional of the Electron Density. Phys. Rev. B 1988, 37 (2), 785-789. https://doi.org/10.1103/PhysRevB.37.785.

(12) Kendall, R. A.; Dunning Jr, T. H.; Harrison, R. J. Electron Affinities of the First-row Atoms Revisited. Systematic Basis Sets and Wave Functions. J. Chem. Phys. 1992, 96 (9), 6796-6806. https://doi.org/10.1063/1.462569.

(13) Peterson, K. A.; Shepler, B. C.; Figgen, D.; Stoll, H. On the Spectroscopic and Thermochemical Properties of $\mathrm{ClO}, \mathrm{BrO}, \mathrm{IO}$, and Their Anions. J. Phys. Chem. A 2006, 110 (51), 13877-13883. https://doi.org/10.1021/jp0658871.

(14) Andersson, M. P.; Uvdal, P. New Scale Factors for Harmonic Vibrational Frequencies Using the B3LYP Density Functional Method with the Triple- $\zeta$ Basis Set 6-311+G(d,p). J. Phys. Chem. A 2005, 109 (12), 2937-2941. https://doi.org/10.1021/jp045733a.

(15) Merrick, J. P.; Moran, D.; Radom, L. An Evaluation of Harmonic Vibrational Frequency Scale Factors. J. Phys. Chem. A 2007, 111 (45), 11683-11700. https://doi.org/10.1021/jp073974n.

(16) Li, X.; Frisch, M. J. Energy-Represented Direct Inversion in the Iterative Subspace within a Hybrid Geometry Optimization Method. J. Chem. Theory Comput. 2006, 2 (3), 835-839. https://doi.org/10.1021/ct050275a.

(17) Fukui, K. The Path of Chemical Reactions - the IRC Approach. Acc. Chem. Res. 1981, 14 (12), 363-368. https://doi.org/10.1021/ar00072a001.

(18) Bauernschmitt, R.; Ahlrichs, R. Treatment of Electronic Excitations within the Adiabatic Approximation of Time Dependent Density Functional Theory. Chem. Phys. Lett. 1996, 256 (4), 454-464. https://doi.org/10.1016/0009-2614(96)00440-X.

(19) Casida, M. E.; Jamorski, C.; Casida, K. C.; Salahub, D. R. Molecular Excitation Energies to High-Lying Bound States from Time-Dependent Density-Functional Response Theory: Characterization and Correction of the Time-Dependent Local Density Approximation Ionization Threshold. J. Chem. Phys. 1998, 108 (11), 4439-4449. https://doi.org/10.1063/1.475855. 
(20) Stratmann, R. E.; Scuseria, G. E.; Frisch, M. J. An Efficient Implementation of TimeDependent Density-Functional Theory for the Calculation of Excitation Energies of Large Molecules. J. Chem. Phys. 1998, 109 (19), 8218-8224. https://doi.org/10.1063/1.477483.

(21) Chantzis, A.; Laurent, A. D.; Adamo, C.; Jacquemin, D. Is the Tamm-Dancoff Approximation Reliable for the Calculation of Absorption and Fluorescence Band Shapes? J. Chem. Theory Comput. 2013, 9 (10), 4517-4525. https://doi.org/10.1021/ct400597f.

(22) Wang, Y.-L.; Wu, G.-S. Improving the TDDFT Calculation of Low-Lying Excited States for Polycyclic Aromatic Hydrocarbons Using the Tamm-Dancoff Approximation. Int. J. Quantum Chem. 2008, 108 (3), 430-439. https://doi.org/10.1002/qua.21510.

(23) Richard, R. M.; Herbert, J. M. Time-Dependent Density-Functional Description of the 1La State in Polycyclic Aromatic Hydrocarbons: Charge-Transfer Character in Disguise? J. Chem. Theory Comput. 2011, 7 (5), 1296-1306. https://doi.org/10.1021/ct100607w.

(24) Hsu, C.-P.; Hirata, S.; Head-Gordon, M. Excitation Energies from Time-Dependent Density Functional Theory for Linear Polyene Oligomers: Butadiene to Decapentaene. $J$. Phys. Chem. A 2001, 105 (2), 451-458. https://doi.org/10.1021/jp0024367.

(25) Cordova, F.; Doriol, L. J.; Ipatov, A.; Casida, M. E.; Filippi, C.; Vela, A. Troubleshooting Time-Dependent Density-Functional Theory for Photochemical Applications: Oxirane. J. Chem. Phys. 2007, 127 (16), 164111. https://doi.org/10.1063/1.2786997.

(26) Perdew, J. P.; Chevary, J. A.; Vosko, S. H.; Jackson, K. A.; Pederson, M. R.; Singh, D. J.; Fiolhais, C. Atoms, Molecules, Solids, and Surfaces: Applications of the Generalized Gradient Approximation for Exchange and Correlation. Phys. Rev. B 1992, 46 (11), 66716687. https://doi.org/10.1103/PhysRevB.46.6671.

(27) Perdew, J. P.; Chevary, J. A.; Vosko, S. H.; Jackson, K. A.; Pederson, M. R.; Singh, D. J.; Fiolhais, C. Erratum: Atoms, Molecules, Solids, and Surfaces: Applications of the Generalized Gradient Approximation for Exchange and Correlation. Phys. Rev. B 1993, 48 (7), 4978-4978. https://doi.org/10.1103/PhysRevB.48.4978.2.

(28) Perdew, J. P.; Burke, K.; Wang, Y. Generalized Gradient Approximation for the Exchange-Correlation Hole of a Many-Electron System. Phys. Rev. B 1996, 54 (23), 16533-16539. https://doi.org/10.1103/PhysRevB.54.16533.

(29) Szczepaniak, U.; Kołos, R.; Gronowski, M.; Chevalier, M.; Guillemin, J.-C.; Turowski, M.; Custer, T.; Crépin, C. Cryogenic Photochemical Synthesis and Electronic 
Spectroscopy of Cyanotetracetylene. J. Phys. Chem. A 2017, 121 (39), 7374-7384. https://doi.org/10.1021/acs.jpca.7b07849.

(30) Lamarre, N.; Gans, B.; Vieira Mendes, L. A.; Gronowski, M.; Guillemin, J.-C.; De Oliveira, N.; Douin, S.; Chevalier, M.; Crépin, C.; Kołos, R.; et al. Excited Electronic Structure of Methylcyanoacetylene Probed by VUV Fourier-Transform Absorption Spectroscopy. J. Quant. Spectrosc. Radiat. Transf. 2016, 182 (Supplement C), 286-295. https://doi.org/10.1016/j.jqsrt.2016.06.020.

(31) Turowski, M.; Szczepaniak, U.; Custer, T.; Gronowski, M.; Kołos, R. Electronic Spectroscopy of Methylcyanodiacetylene $\left(\mathrm{CH}_{3} \mathrm{C}_{5} \mathrm{~N}\right)$. ChemPhysChem 2016, 17 (24), 4068-4078. https://doi.org/10.1002/cphc.201600949.

(32) Yanai, T.; Tew, D. P.; Handy, N. C. A New Hybrid Exchange-Correlation Functional Using the Coulomb-Attenuating Method (CAM-B3LYP). Chem. Phys. Lett. 2004, 393 (13), 51-57. https://doi.org/10.1016/j.cplett.2004.06.011.

(33) Peterson, K. A.; Figgen, D.; Goll, E.; Stoll, H.; Dolg, M. Systematically Convergent Basis Sets with Relativistic Pseudopotentials. II. Small-Core Pseudopotentials and Correlation Consistent Basis Sets for the Post-d Group 16-18 Elements. J. Chem. Phys. 2003, 119 (21), 11113-11123. https://doi.org/10.1063/1.1622924.

(34) Barone, V. Vibrational Zero-Point Energies and Thermodynamic Functions beyond the Harmonic Approximation. J. Chem. Phys. 2004, 120 (7), 3059-3065. https://doi.org/10.1063/1.1637580.

(35) Barone, V. Anharmonic Vibrational Properties by a Fully Automated Second-Order Perturbative Approach. J. Chem. Phys. 2005, 122 (1), 014108. https://doi.org/10.1063/1.1824881.

(36) Bloino, J.; Barone, V. A Second-Order Perturbation Theory Route to Vibrational Averages and Transition Properties of Molecules: General Formulation and Application to Infrared and Vibrational Circular Dichroism Spectroscopies. J. Chem. Phys. 2012, 136 (12), 124108. https://doi.org/10.1063/1.3695210.

(37) Frisch, M. J.; Trucks, G. W.; Schlegel, H. B.; Scuseria, G. E.; Robb, M. A.; Cheeseman, J. R.; Scalmani, G.; Barone, V.; Mennucci, B.; Petersson, G. A. Gaussian 09; Gaussian, Inc., Wallingford CT, 2009. 
(38) Christiansen, O. Vibrational Structure Theory: New Vibrational Wave Function Methods for Calculation of Anharmonic Vibrational Energies and Vibrational Contributions to Molecular Properties. Phys. Chem. Chem. Phys. 2007, 9 (23), 2942-2953. https://doi.org/10.1039/B618764A.

(39) Rauhut, G.; Hrenar, T. A Combined Variational and Perturbational Study on the Vibrational Spectrum of $\mathrm{P}_{2} \mathrm{~F}_{4}$. Chem. Phys. 2008, 346 (1), 160-166. https://doi.org/10.1016/j.chemphys.2008.01.039.

(40) Christiansen, O. Møller-Plesset Perturbation Theory for Vibrational Wave Functions. J. Chem. Phys. 2003, 119 (12), 5773-5781. https://doi.org/10.1063/1.1601593.

(41) Hampel, C.; Peterson, K. A.; Werner, H.-J. A Comparison of the Efficiency and Accuracy of the Quadratic Configuration Interaction (QCISD), Coupled Cluster (CCSD), and Brueckner Coupled Cluster (BCCD) Methods. Chem. Phys. Lett. 1992, 190 (1), 1-12. https://doi.org/10.1016/0009-2614(92)86093-W.

(42) Deegan, M. J. O.; Knowles, P. J. Perturbative Corrections to Account for Triple Excitations in Closed and Open Shell Coupled Cluster Theories. Chem. Phys. Lett. 1994, 227 (3), 321-326. https://doi.org/10.1016/0009-2614(94)00815-9.

(43) Pople, J. A.; Head-Gordon, M.; Raghavachari, K. Quadratic Configuration Interaction. A General Technique for Determining Electron Correlation Energies. J. Chem. Phys. 1987, 87 (10), 5968-5975. https://doi.org/10.1063/1.453520.

(44) Raghavachari, K.; Trucks, G. W.; Pople, J. A.; Head-Gordon, M. A Fifth-Order Perturbation Comparison of Electron Correlation Theories. Chem. Phys. Lett. 1989, 157 (6), 479-483. https://doi.org/10.1016/S0009-2614(89)87395-6.

(45) Bartlett, R. J.; Watts, J. D.; Kucharski, S. A.; Noga, J. Non-Iterative Fifth-Order Triple and Quadruple Excitation Energy Corrections in Correlated Methods. Chem. Phys. Lett. 1990, 165 (6), 513-522. https://doi.org/10.1016/0009-2614(90)87031-L.

(46) Stanton, J. F. Why CCSD(T) Works: A Different Perspective. Chem. Phys. Lett. 1997, 281 (1), 130-134. https://doi.org/10.1016/S0009-2614(97)01144-5.

(47) Rauhut, G. Efficient Calculation of Potential Energy Surfaces for the Generation of Vibrational Wave Functions. J. Chem. Phys. 2004, 121 (19), 9313-9322. https://doi.org/10.1063/1.1804174. 
(48) Hrenar, T.; Werner, H.-J.; Rauhut, G. Accurate Calculation of Anharmonic Vibrational Frequencies of Medium Sized Molecules Using Local Coupled Cluster Methods. J. Chem. Phys. 2007, 126 (13), 134108. https://doi.org/10.1063/1.2718951.

(49) Neff, M.; Rauhut, G. Erratum: "Toward Large Scale Vibrational Configuration Interaction Calculations" [J. Chem. Phys. 131, 124129 (2009)]. J. Chem. Phys. 2009, 131 (22), 229901. https://doi.org/10.1063/1.3273188.

(50) Rauhut, G.; El Azhary, A.; Eckert, F.; Schumann, U.; Werner, H.-J. Impact of Local Approximations on MP2 Vibrational Frequencies. Spectrochim. Acta. A. Mol. Biomol. Spectrosc. 1999, 55 (3), 647-658. https://doi.org/10.1016/S1386-1425(98)00268-6.

(51) Hrenar, T.; Rauhut, G.; Werner, H.-J. Impact of Local and Density Fitting Approximations on Harmonic Vibrational Frequencies. J. Phys. Chem. A 2006, 110 (5), 2060-2064. https://doi.org/10.1021/jp055578f.

(52) Eckert, F.; Pulay, P.; Werner, H.-J. Ab Initio Geometry Optimization for Large Molecules. J. Comput. Chem. 1997, 18 (12), 1473-1483. https://doi.org/10.1002/(SICI)1096987X(199709)18:12<1473::AID-JCC5>3.0.CO;2-G.

(53) Werner, H.-J.; Knowles, P. J.; Knizia, G.; Manby, F. R.; Schütz, M. Molpro: A GeneralPurpose Quantum Chemistry Program Package. Wiley Interdiscip. Rev. Comput. Mol. Sci. 2012, 2 (2), 242-253. https://doi.org/10.1002/wcms.82.

(54) Werner, H.-J.; Knowles, P. J.; Knizia, G.; Manby, F. R.; Schütz, M.; Celani, P.; Korona, T.; Lindh, R.; Mitrushenkov, A.; Rauhut, G.; et al. MOLPRO, Version 2012.1, a Package of Ab Initio Programs, See Http://Www.Molpro.Net.

(55) Chemcraft - Graphical program for visualization of quantum chemistry computations, www.chemcraftprog.com http://www.chemcraftprog.com/ (accessed Oct 28, 2017).

(56) Kloster-Jensen, E.; Dyrssen, D.; Johansson, L.; Norén, B.; Munch-Petersen, J. Unsaturated Hydrogen-Free Halogeno Cyano Compounds. II. Synthesis and General Properties of Bromocyanoacetylene. Acta Chem. Scand. 1963, 17, 1862-1865. https://doi.org/10.3891/acta.chem.scand.17-1862.

(57) Bruston, P.; Poncet, H.; Raulin, F.; Cossart-Magos, C.; Courtin, R. UV Spectroscopy of Titan's Atmosphere, Planetary Organic Chemistry, and Prebiological Synthesis. Icarus 1989, 78 (1), 38-53. https://doi.org/10.1016/0019-1035(89)90068-7. 
(58) Job, V. A.; King, G. W. The Electronic Spectrum of Cyanoacetylene: Part I. Analysis of the 2600-Å System. J. Mol. Spectrosc. 1966, 19 (1), 155-177. https://doi.org/10.1016/0022-2852(66)90238-4.

(59) Job, V. A.; King, G. W. The Electronic Spectrum of Cyanoacetylene: Part II. Analysis of the 2300-Å System. J. Mol. Spectrosc. 1966, 19 (1), 178-184. https://doi.org/10.1016/0022-2852(66)90239-6.

(60) NIST Office of Data and Informatics. NIST Chemistry WebBook https://webbook.nist.gov/chemistry/ (accessed Sep 27, 2019). https://doi.org/10.18434/T4D303. NIST Computational Chemistry Comparison and Benchmark Database, NIST Standard Reference Database Number 101 Release 20, August 2019, Editor: Russell D. Johnson III Http://Cccbdb.Nist.Gov/.

(62) Khriachtchev, L.; Lignell, A.; Tanskanen, H.; Lundell, J.; Kiljunen, H.; Räsänen, M. Insertion of Noble Gas Atoms into Cyanoacetylene: An Ab Initio and Matrix Isolation Study. J. Phys. Chem. A 2006, 110 (42), 11876-11885. https://doi.org/10.1021/jp063731f.

(63) Guennoun, Z.; Couturier-Tamburelli, I.; Piétri, N.; Aycard, J. P. UV Photoisomerisation of Cyano and Dicyanoacetylene: The First Identification of CCNCH and CCCNCN Isomers - Matrix Isolation, Infrared and Ab Initio Study. Chem. Phys. Lett. 2003, 368 (5-6), 574583. https://doi.org/10.1016/S0009-2614(02)01898-5.

(64) Kołos, R.; Sobolewski, A. L. The Infrared Spectroscopy of HNCCC: Matrix Isolation and Density Functional Theory Study. Chem. Phys. Lett. 2001, 344 (5-6), 625-630. https://doi.org/10.1016/S0009-2614(01)00793-X.

(65) Goldberg, N.; Schwarz, H. Experimental Evidence for the Existence of Cyanovinylidene :C:C(H)CN. Gas-Phase Characterization of a Possible Interstellar Molecule. J. Phys. Chem. 1994, 98 (12), 3080-3082. https://doi.org/10.1021/j100063a005.

(66) Hu, C. H.; Schaefer, H. F. Cyanovinylidene: An Observable Unsaturated Carbene and a Possible Interstellar Molecule. J. Phys. Chem. 1993, 97 (41), 10681-10686. https://doi.org/10.1021/j100143a026.

(67) Kołos, R.; Gronowski, M.; Dobrowolski, J. Cz. Prospects for the Detection of Interstellar Cyanovinylidene. Astrophys. J. 2009, 701 (1), 488-492. https://doi.org/10.1088/0004637X/701/1/488. 
(68) Bally, T. Matrix Isolation. In Reactive Intermediate Chemistry; John Wiley \& Sons, Ltd, 2005; pp 795-845. https://doi.org/10.1002/0471721492.ch17.

(69) Yang, X.; Maeda, S.; Ohno, K. Global Analysis of Reaction Pathways on the Potential Energy Surface of Cyanoacetylene by the Scaled Hypersphere Search Method. Chem. Phys. Lett. 2006, 418 (1), 208-216. https://doi.org/10.1016/j.cplett.2005.10.132.

(70) Kołos, R.; Gronowski, M.; Botschwina, P. Matrix Isolation IR Spectroscopic and Ab Initio Studies of $\mathrm{C}_{3} \mathrm{~N}^{-}$and Related Species. J. Chem. Phys. 2008, 128 (15), 154305. https://doi.org/10.1063/1.2902289.

(71) Turowski, M.; Gronowski, M.; Boyé-Péronne, S.; Douin, S.; Monéron, L.; Crépin, C.; Kołos, R. The $\mathrm{C}_{3} \mathrm{~N}^{-}$Anion: First Detection of Its Electronic Luminescence in Rare Gas Solids. J. Chem. Phys. 2008, 128 (16), 164304. https://doi.org/10.1063/1.2904876. 
Table 1. Vertical excitation energies and oscillator strengths for electronic transitions of $\mathrm{IC}_{3} \mathrm{~N}$, as computed with CAM-B3LYP/aug-cc-pVQZ.

\begin{tabular}{|l|l|l|}
\hline State & $\begin{array}{l}\text { Vertical } \\
\text { energy } \\
\text { eV (nm) }\end{array}$ & f \\
\hline$A^{1} \Sigma^{-}$ & $4.95(251)$ & 0 \\
\hline$B^{1} \Delta$ & $5.07(245)$ & 0 \\
\hline$C^{1} \Delta$ & $5.11(243)$ & 0 \\
\hline$D^{1} \Pi$ & $6.90(180)$ & 0.07 \\
\hline$E^{1} \Sigma^{+}$ & $7.10(175)$ & 1.3 \\
\hline
\end{tabular}

${ }^{a}$ States designated as the linear ones, irrespective of their equilibrium geometries, to ease the comparison with other cyanoacetylene family molecules. 
Table 2. Comparison of computed and experimental IR absorption data for $\mathrm{IC}_{3} \mathrm{~N}$.

\begin{tabular}{|c|c|c|c|c|c|c|c|c|c|c|c|}
\hline \multirow[b]{3}{*}{$\begin{array}{l}\text { Mode, } \\
\text { symmetry }\end{array}$} & \multicolumn{5}{|c|}{$\mathrm{B} 3 \mathrm{LYP}^{a}$} & \multicolumn{3}{|c|}{$\operatorname{CCSD}(\mathrm{T})^{b}$} & \multicolumn{2}{|c|}{$\begin{array}{l}\text { Experimental } \\
\text { frequency, } \mathrm{cm}^{-1}\end{array}$} & \multirow{3}{*}{$\begin{array}{l}\mathrm{Re} \\
1 . \\
\text { int }\end{array}$} \\
\hline & \multirow[b]{2}{*}{$\begin{array}{l}\text { Vharm } \\
{ }^{c} \\
\text { scal } \\
\text { ed, } \\
\mathrm{cm}^{-1}\end{array}$} & \multirow{2}{*}{$\begin{array}{l}\text { IR } \\
\text { int. } \\
\text { harm. } \\
\text { ' } \\
\mathrm{km} / \\
\text { mol } \\
\text { (relat } \\
\text { ive } \\
\text { int.) }\end{array}$} & \multirow[b]{2}{*}{$\begin{array}{l}\text { Ram } \\
\text { an } \\
\text { activi } \\
\text { ty }^{d}\end{array}$} & \multirow[b]{2}{*}{$\begin{array}{l}\text { Vahar } \\
\mathrm{m}, \\
\mathrm{cm}^{-} \\
1\end{array}$} & \multirow[b]{2}{*}{$\begin{array}{l}\text { Iharm/ } \\
\mathrm{km} \\
\mathrm{mol}^{-1}\end{array}$} & \multirow[b]{2}{*}{$\begin{array}{l}\text { Vhar } \\
\mathrm{m} \text {, } \\
\mathrm{cm}^{-} \\
1\end{array}$} & \multicolumn{2}{|c|}{$v_{\text {aharm}}, \mathrm{cm}^{-1}$} & \multirow[b]{2}{*}{$\begin{array}{l}\mathrm{IC}_{3} \mathrm{~N}, \\
\text { gas }^{e} \\
\text { (solid) }{ }^{f}\end{array}$} & \multirow[b]{2}{*}{$\mathrm{IC}_{3} \mathrm{~N}: \mathrm{Ar}$} & \\
\hline & & & & & & & $\begin{array}{l}\text { VS } \\
\mathrm{CF}\end{array}$ & $\begin{array}{l}\mathrm{VM} \\
\mathrm{P} 2\end{array}$ & & & \\
\hline$v_{1}, \sigma$ & $\begin{array}{l}226 \\
2\end{array}$ & $\begin{array}{l}174 \\
(100)\end{array}$ & 1381 & $\begin{array}{l}232 \\
1\end{array}$ & 161 & $\begin{array}{l}23 \\
16\end{array}$ & $\begin{array}{l}227 \\
6\end{array}$ & $\begin{array}{l}227 \\
3\end{array}$ & $\begin{array}{l}2270 \\
(2262)\end{array}$ & 2266.4 & $\begin{array}{l}10 \\
0\end{array}$ \\
\hline$v_{2}, \sigma$ & $\begin{array}{l}212 \\
6\end{array}$ & $\begin{array}{l}21 \\
(12)\end{array}$ & 80 & $\begin{array}{l}218 \\
5\end{array}$ & 15 & $\begin{array}{l}21 \\
55\end{array}$ & $\begin{array}{l}211 \\
8\end{array}$ & $\begin{array}{l}211 \\
5\end{array}$ & $\begin{array}{l}2131 \\
(21130\end{array}$ & 2123.1 & 13 \\
\hline$v_{3}, \sigma$ & 983 & $\begin{array}{l}1 \\
(0.6)\end{array}$ & 1084 & 994 & 0.19 & $\begin{array}{l}10 \\
00\end{array}$ & 988 & $\begin{array}{l}100 \\
9\end{array}$ & $\begin{array}{l}1031 \\
(1037)\end{array}$ & 1031.1 & $\begin{array}{l}0 . \\
8\end{array}$ \\
\hline$v_{4}, \sigma$ & 347 & 0 & 645 & 359 & 0.01 & $\begin{array}{l}35 \\
6\end{array}$ & 353 & 353 & $\begin{array}{l}364 \\
(349)\end{array}$ & $\begin{array}{l}\text { out of } \\
\text { range }\end{array}$ & \\
\hline$v_{5}, \pi$ & 517 & $\begin{array}{l}4 \\
(2.3)\end{array}$ & 1.5 & 532 & 5 & $\begin{array}{l}49 \\
4\end{array}$ & 498 & 498 & $\begin{array}{l}496 \\
(483)\end{array}$ & $\begin{array}{l}493.9+4 \\
94.9\end{array}$ & $\begin{array}{l}5 . \\
2\end{array}$ \\
\hline$v_{6}, \pi$ & 309 & $\begin{array}{l}24 \\
(14)\end{array}$ & 341 & 327 & 15 & $\begin{array}{l}30 \\
3\end{array}$ & 308 & 304 & $\begin{array}{l}309 \\
(323,32 \\
2 \mathrm{sh})\end{array}$ & $\begin{array}{l}\text { out of } \\
\text { range }\end{array}$ & \\
\hline$v_{7}, \pi$ & 108 & 0 & 271 & 114 & 1.0 & $\begin{array}{l}11 \\
0\end{array}$ & 124 & 116 & $\begin{array}{l}\text { (118,13 } \\
4)\end{array}$ & $\begin{array}{l}\text { out of } \\
\text { range }\end{array}$ & \\
\hline $\begin{array}{l}v_{2}+v_{4}+v_{6} \text { or } \\
v_{1}+2 v_{7}+v_{6}\end{array}$ & $\begin{array}{l}278 \\
1\end{array}$ & & & & & & & & & 2753.8 & $\begin{array}{l}0 . \\
1\end{array}$ \\
\hline$v_{1}+v_{4}+v_{7}$ & 271 & & & & & & & & & 2717.9 & 0. \\
\hline
\end{tabular}




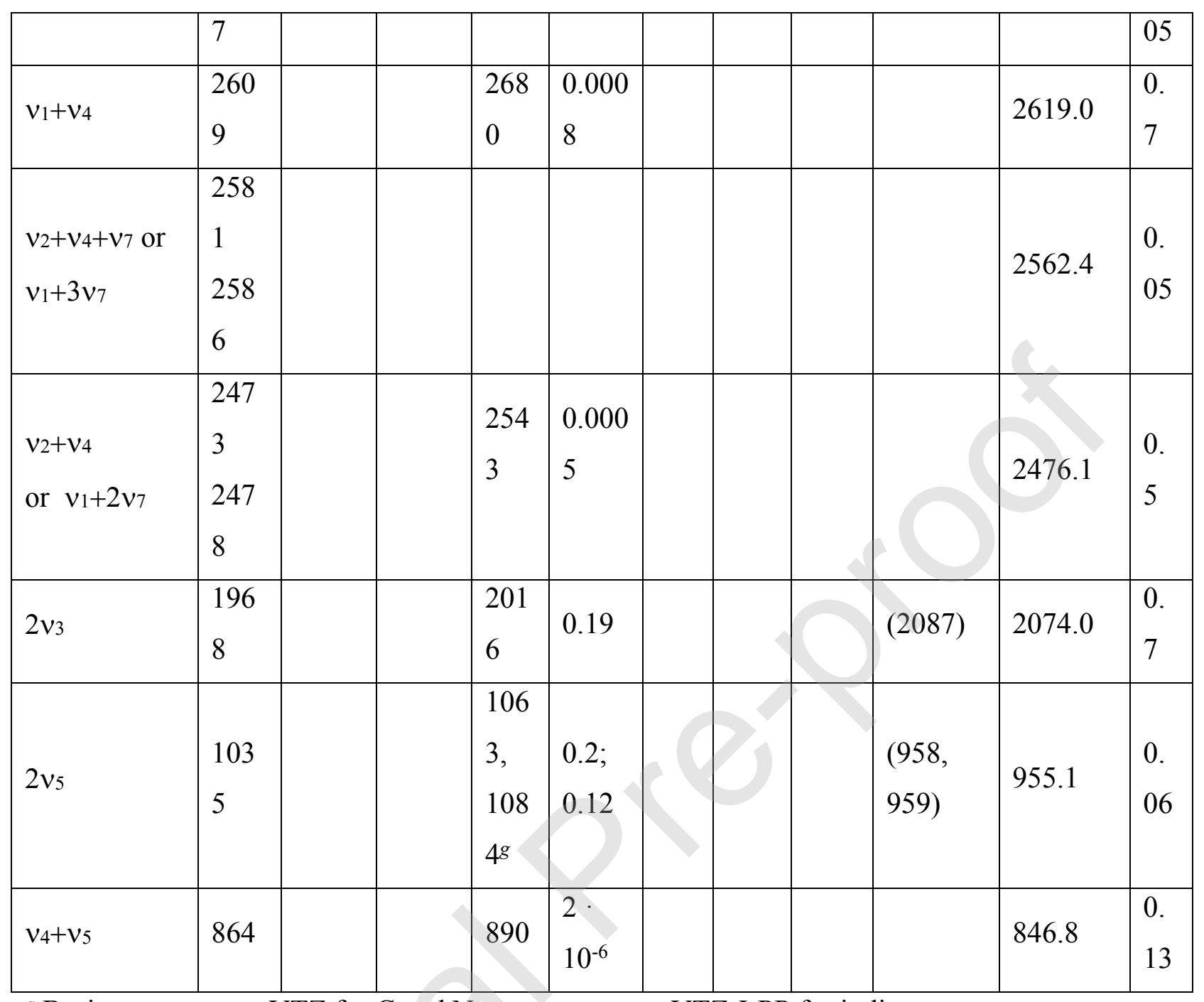

${ }^{a}$ Basis sets aug-cc-pVTZ for $\mathrm{C}$ and $\mathrm{N}$ atoms, aug-cc-pVTZ-I-PP for iodine.

${ }^{b}$ Non-augmented versions of the basis sets used in DFT calculations were applied.

${ }^{c}$ Harmonic frequencies scaled by 0.96 (see Table S4 in the Supplementary material for an extended list of calculated overtone and combination bands).

${ }^{d}$ Harmonic approximation.

${ }^{e}$ Ref. 60 .

${ }^{f}$ Ref. 6, values from Raman spectra if IR data not available, sh - shoulder band.

${ }^{g}$ Ref. 61 . 
Table 3. Comparison of theoretically predicted and experimental IR absorption data for $\mathrm{IC}_{2} \mathrm{NC}$.

\begin{tabular}{|c|c|c|c|c|c|c|c|c|c|c|}
\hline \multirow{3}{*}{$\begin{array}{l}\text { Mode, } \\
\text { symmetr } \\
\text { y }\end{array}$} & \multicolumn{5}{|c|}{$\mathrm{B} 3 \mathrm{LYP}^{a}$} & \multicolumn{3}{|c|}{$\operatorname{CCSD}(\mathrm{T})^{b}$} & \multicolumn{2}{|c|}{$\begin{array}{l}\text { Experiment } \\
\mathrm{IC}_{3} \mathrm{~N} \text { :Ar matrix }\end{array}$} \\
\hline & \multirow{2}{*}{$\begin{array}{l}V_{\text {harm, }} \\
\text { scale } \\
\mathrm{d} \\
\mathrm{cm}^{-1} \mathrm{c}\end{array}$} & \multirow{2}{*}{$\begin{array}{l}\text { IR int. } \\
\text { harm. } \\
\text { (relative) } \\
\text {, } \mathrm{km} / \mathrm{mol}\end{array}$} & \multirow{2}{*}{$\begin{array}{l}\text { Raman } \\
\text { act. } \\
\text { (relative) } \\
d\end{array}$} & \multirow{2}{*}{$\begin{array}{l}V_{\text {aharm }} \\
, \\
\mathrm{cm}^{-1}\end{array}$} & \multirow{2}{*}{$\begin{array}{l}\mathrm{I}_{\text {harm }} \\
\mathrm{km} / \mathrm{mo} \\
1\end{array}$} & \multirow[b]{2}{*}{$\begin{array}{l}v_{\text {harm }} \\
\mathrm{cm}^{-1}\end{array}$} & \multicolumn{2}{|c|}{$v_{\text {aharm }}, \mathrm{cm}^{-1}$} & \multirow[b]{2}{*}{$v, \mathrm{~cm}^{-1}$} & \multirow{2}{*}{$\begin{array}{l}\text { Relativ } \\
\text { e IR } \\
\text { intensit } \\
\text { y }\end{array}$} \\
\hline & & & & & & & $\begin{array}{l}\text { VSC } \\
\mathrm{F}\end{array}$ & $\begin{array}{l}\text { VMP } \\
2\end{array}$ & & \\
\hline $1, \sigma$ & 2228 & $2(1.1)$ & $\begin{array}{l}2054 \\
(100)\end{array}$ & 2287 & $2(1.2)$ & $\begin{array}{l}229 \\
5\end{array}$ & 2250 & 2253 & $\begin{array}{l}\text { not } \\
\text { observe } \\
\text { d }\end{array}$ & 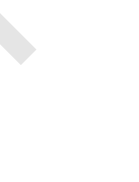 \\
\hline $2, \sigma$ & 2039 & $\begin{array}{l}179 \\
(100)\end{array}$ & $144(7.0)$ & 2090 & $\begin{array}{l}168 \\
(100)\end{array}$ & $\begin{array}{l}207 \\
9\end{array}$ & 2036 & 2033 & 2050.2 & 100 \\
\hline $3, \sigma$ & 1038 & $6(3.4)$ & $\begin{array}{l}1238 \\
(60)\end{array}$ & 1078 & $3(1.8)$ & $\begin{array}{l}105 \\
6\end{array}$ & 1042 & 1048 & 1054.5 & 1.3 \\
\hline $4, \sigma$ & 349 & $0(0)$ & $423(21)$ & 358 & $\begin{array}{l}0.4 \\
(0.2)\end{array}$ & 361 & 358 & 357 & $\begin{array}{l}\text { out of } \\
\text { range }\end{array}$ & \\
\hline $5, \pi$ & 442 & $2(1.1)$ & $64(3.1)$ & 449 & $\begin{array}{l}0.12 \\
(0.1)\end{array}$ & 422 & 426 & 424 & $\begin{array}{l}\text { not } \\
\text { observe } \\
\text { d }\end{array}$ & \\
\hline $6, \pi$ & 270 & $17(9.5)$ & 397 (19) & 278 & $\begin{array}{l}11 \\
(6.5)\end{array}$ & 264 & 277 & 274 & $\begin{array}{l}\text { out of } \\
\text { range }\end{array}$ & \\
\hline $7, \pi$ & 112 & $0(0)$ & $324(16)$ & 116 & $0.3(.2)$ & 113 & 131 & 116 & $\begin{array}{l}\text { out of } \\
\text { range }\end{array}$ & \\
\hline
\end{tabular}

${ }^{a}$ Basis set aug-cc-pVTZ with aug-cc-pVTZ-PP for I atom.

${ }^{b}$ Basis set cc-pVTZ with cc-pVTZ-PP for I atom.

${ }^{c}$ DFT frequencies scaled by 0.96 (see Table S8 in the Supplementary material for the predicted overtone and combination bands).

${ }^{d}$ Harmonic approximation. 
Table 4. Comparison of the theoretically predicted and experimental IR absorption data for $\mathrm{ICNC}_{2}$.

\begin{tabular}{|c|c|c|c|c|c|c|c|}
\hline \multirow{3}{*}{ Mode } & \multicolumn{5}{|c|}{ Computations } & \multirow{2}{*}{\multicolumn{2}{|c|}{$\begin{array}{l}\text { Experiment } \\
\text { Ar matix }\end{array}$}} \\
\hline & \multicolumn{4}{|c|}{ B3LYP $^{a}$} & \multirow{2}{*}{$\begin{array}{l}\operatorname{CCSD}(\mathrm{T})^{b} \\
v_{\text {harm }}, \mathrm{cm}^{-1}\end{array}$} & & \\
\hline & $\begin{array}{l}V_{\text {harm, }}^{c}{ }^{c} \\
\mathbf{c m}^{-1}\end{array}$ & $\begin{array}{l}\text { Iharm, } \\
\text { km mol}^{-1} \\
\text { (rel. int.) }\end{array}$ & $V_{\text {anharm }}, \mathbf{c m}^{-1}$ & $\begin{array}{l}\text { Ianharm, } \\
\text { km mol}^{-1} \\
\text { (rel. int.) }\end{array}$ & & Freq, $\mathbf{c m}^{-1}$ & I rel \\
\hline$v_{1}$ & 2189 & $660(100)$ & 2231 & $590(89)$ & 2203 & 2172.5 & 71 \\
\hline$v_{2}$ & 1950 & $630(96)$ & 1988 & $660(100)$ & 1966 & 1934.8 & 100 \\
\hline$v_{3}$ & 1030 & $16(2.4)$ & 1074 & $14(2.1)$ & 1043 & not observed & \\
\hline$v_{4}$ & 357 & $1.4(0.2)$ & 378 & $0.7(0.1)$ & 366 & not observed & \\
\hline$v_{5}$ & 457 & $5.7(0.9)$ & 458 & $6.7(1.0)$ & 449 & not observed & \\
\hline$v_{6}$ & 198 & $6.8(1.0)$ & 177 & $5.8(0.9)$ & 185 & not observed & \\
\hline$v_{7}$ & 63 & $6.6(1.0)$ & 32 & $6.6(1.0)$ & 61 & not observed & \\
\hline
\end{tabular}

${ }^{a}$ Basis set aug-cc-pVTZ with aug-cc-pVTZ-PP for I atom.

${ }^{b}$ Basis set cc-pVTZ with cc-pVTZ-PP for I atom.

${ }^{c}$ DFT frequencies scaled with 0.96 (see Table S9 in the Supplementary material for the list of calculated overtone and combination bands). 